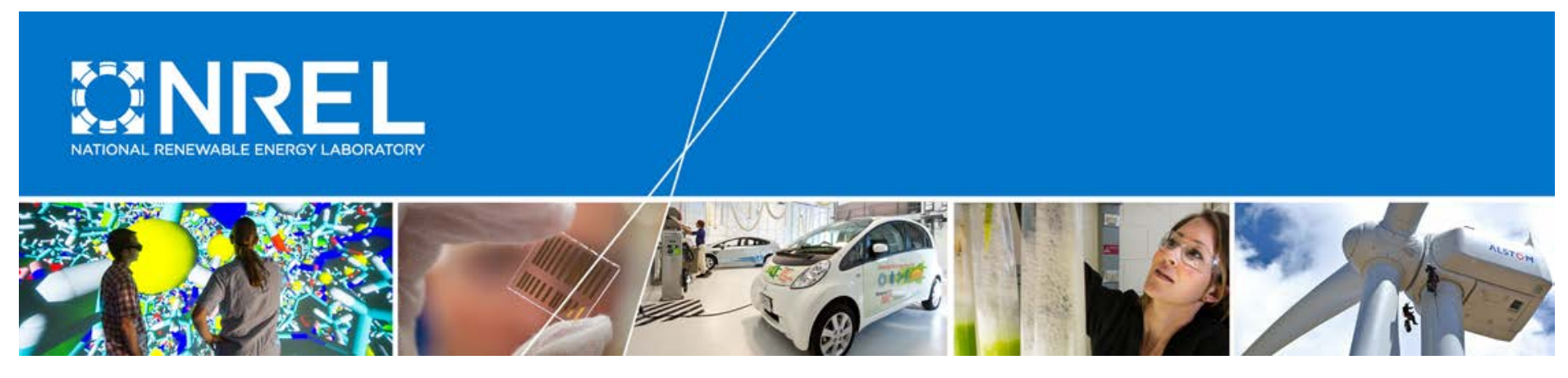

\title{
Technologies to Increase PV Hosting Capacity in Distribution Feeders
}

\section{Preprint}

\author{
Fei Ding, Barry Mather, and Peter Gotseff \\ National Renewable Energy Laboratory \\ Presented at the 2016 IEEE PES General Meeting \\ Boston, Massachusetts \\ July 17-21, 2016
}

(C) 2016 IEEE. Personal use of this material is permitted. Permission from IEEE must be obtained for all other uses, in any current or future media, including reprinting/republishing this material for advertising or promotional purposes, creating new collective works, for resale or redistribution to servers or lists, or reuse of any copyrighted component of this work in other works.

NREL is a national laboratory of the U.S. Department of Energy Office of Energy Efficiency \& Renewable Energy Operated by the Alliance for Sustainable Energy, LLC

This report is available at no cost from the National Renewable Energy Laboratory (NREL) at www.nrel.gov/publications.

\section{Conference Paper}

NREL/CP-5D00-65995

August 2016

Contract No. DE-AC36-08G028308 


\section{NOTICE}

The submitted manuscript has been offered by an employee of the Alliance for Sustainable Energy, LLC (Alliance), a contractor of the US Government under Contract No. DE-AC36-08GO28308. Accordingly, the US Government and Alliance retain a nonexclusive royalty-free license to publish or reproduce the published form of this contribution, or allow others to do so, for US Government purposes.

This report was prepared as an account of work sponsored by an agency of the United States government. Neither the United States government nor any agency thereof, nor any of their employees, makes any warranty, express or implied, or assumes any legal liability or responsibility for the accuracy, completeness, or usefulness of any information, apparatus, product, or process disclosed, or represents that its use would not infringe privately owned rights. Reference herein to any specific commercial product, process, or service by trade name, trademark, manufacturer, or otherwise does not necessarily constitute or imply its endorsement, recommendation, or favoring by the United States government or any agency thereof. The views and opinions of authors expressed herein do not necessarily state or reflect those of the United States government or any agency thereof.

This report is available at no cost from the National Renewable Energy Laboratory (NREL) at www.nrel.gov/publications.

Available electronically at SciTech Connect http:/www.osti.gov/scitech

Available for a processing fee to U.S. Department of Energy and its contractors, in paper, from:

U.S. Department of Energy

Office of Scientific and Technical Information

P.O. Box 62

Oak Ridge, TN 37831-0062

OSTI http://www.osti.gov

Phone: 865.576.8401

Fax: 865.576.5728

Email: reports@osti.gov

Available for sale to the public, in paper, from:

U.S. Department of Commerce

National Technical Information Service

5301 Shawnee Road

Alexandria, VA 22312

NTIS http://www.ntis.gov

Phone: 800.553 .6847 or 703.605 .6000

Fax: 703.605.6900

Email: orders@ntis.gov 


\title{
Technologies to Increase PV Hosting Capacity in Distribution Feeders
}

\author{
Fei Ding, Member, IEEE, Barry Mather, Senior Member, IEEE and Peter Gotseff, Member, IEEE
}

\begin{abstract}
This paper studies the distributed photovoltaic (PV) hosting capacity in distribution feeders by using the stochastic analysis approach. Multiple scenario simulations are conducted to analyze several factors that affect PV hosting capacity, including the existence of voltage regulator, PV location, the power factor of PV inverter and Volt/VAR control. Based on the conclusions obtained from simulation results, three approaches are then proposed to increase distributed PV hosting capacity, which can be formulated as the optimization problem to obtain the optimal solution. All technologies investigated in this paper utilize only existing assets in the feeder and therefore are implementable for a low cost. Additionally, the tool developed for these studies is described.
\end{abstract}

Index Terms - photovoltaic (PV), hosting capacity, voltage improvement, distribution system, smart inverter, volt/var control, feeder reconfiguration.

\section{INTRODUCTION}

$\mathrm{V}$ ARIOUS incentive mechanisms have stimulated the installation of solar PVs for both commercial and residential applications. Hosting capacity is defined as the total PV capacity that can be accommodated on a given feeder without adversely impacting voltage, protection and power quality and with no feeder upgrades or modifications. Understanding the hosting capacity of a feeder can help utilities to make timely decisions for PV interconnection requests and ensure that distribution grids continue to operate reliably. While both utility-scale and small-scale PV systems are prevalent the analysis presented in this paper only studies the hosting capacity for distributed small-scale PV systems.

Most utilities accept a $15 \%$ PV penetration threshold [1] that is defined as the ratio of PV capacity on a line section to peak load, assuming no other distributed generation. However, this criterion does not take into account PV locational impact or individual feeder characteristics. This paper investigates the sensitivity of PV hosting capacity with respect to feeder characteristics, PV locations, PV inverter power factors and volt/var control. Although multiple criteria including voltage, current, power quality and protection should be considered to evaluate the PV hosting capacity, the most significant criterion that must be first considered is voltage. Thus, voltage limits including overvoltage, voltage unbalance and voltage deviation are considered as the evaluation criterion to define the allowed maximum PV capacity in this paper. Based on the results of multiple-scenario simulations, three approaches are then proposed to maximize PV hosting capacity using optimization, which include feeder reconfiguration, optimal

F. Ding (email: Fei.Ding@nrel.gov), B. Mather and P. Gotseff are all with National Renewable Energy Laboratory, Golden CO 80214 USA.
PV inverter power factor setting and volt/var optimization. All studies are accomplished using the simulation tool described in this paper which was developed by the authors.

\section{FEEDER ChARACTERISTICS AND DistribUTED PV HOSTING CAPACITY}

\section{A. Feeder Characteristics}

Fifteen feeders from four different utilities are used to study the PV hosting capacity. Fig. 1 shows some key characteristics of these fifteen test feeders, including voltage class, maximum load power, total number of customers, feeder length, maximum impedance magnitude for all primary buses, weighted average magnitude for all primary buses, maximum load, total number of capacitors, total capacitor kvar and total number of line voltage regulators.

Feeder-1 is $4 \mathrm{kV}$ and feeder- 6 is $16 \mathrm{kV}$, and all other feeders are $12 \mathrm{kV}$. Feeder- 4 has the most customers, but feeder-12 has the highest load power among fifteen test feeders. Feeders 1, 2, 3, 4, 6, 8, 10 are all less than $5 \mathrm{~km}$ and feeder-7 is around $13 \mathrm{~km}$. Feeders 3 and 6 have very low impedances, which are lower than $3 \Omega$, and feeder 13 has the highest primary impedance, $17.8 \Omega$. All feeders are equipped with capacitors and feeder-12 has the largest kVAR support from the capacitors. Line voltage regulators only exist in feeders $4,7,12,13,14$ and 15 .

\section{B. PV Hosting Capacity}

$\mathrm{PV}$ hosting capacity is the total PV power that can be accommodated on a given feeder without any adverse impacts. This paper uses a stochastic analysis approach that was described in [2]. The stochastic nature of the analysis takes into account the uncertainty in the size and location of potentially installed PV systems by generating PV deployment scenarios randomly. Fig. 2 describes the Monte Carlo procedure to generate PV deployments. PV locations are selected randomly from all customers, and each PV location is assigned one aggregate PV unit. Residential or commercial PV types are determined by the classification of customer load. This paper studies the hosting capacity of distributed smallscale rooftop PVs, and the probability density functions of both residential and commercial PV power are acquired from the California Solar Initiative's PV statistics data. These distributions are then sampled to determine the size of each PV unit. The procedure is repeated to increase PV customer penetration (the ratio between total PVs and total customers) by a fixed step (e.g. 2\%) until 100\% PV customer penetration achieved. 

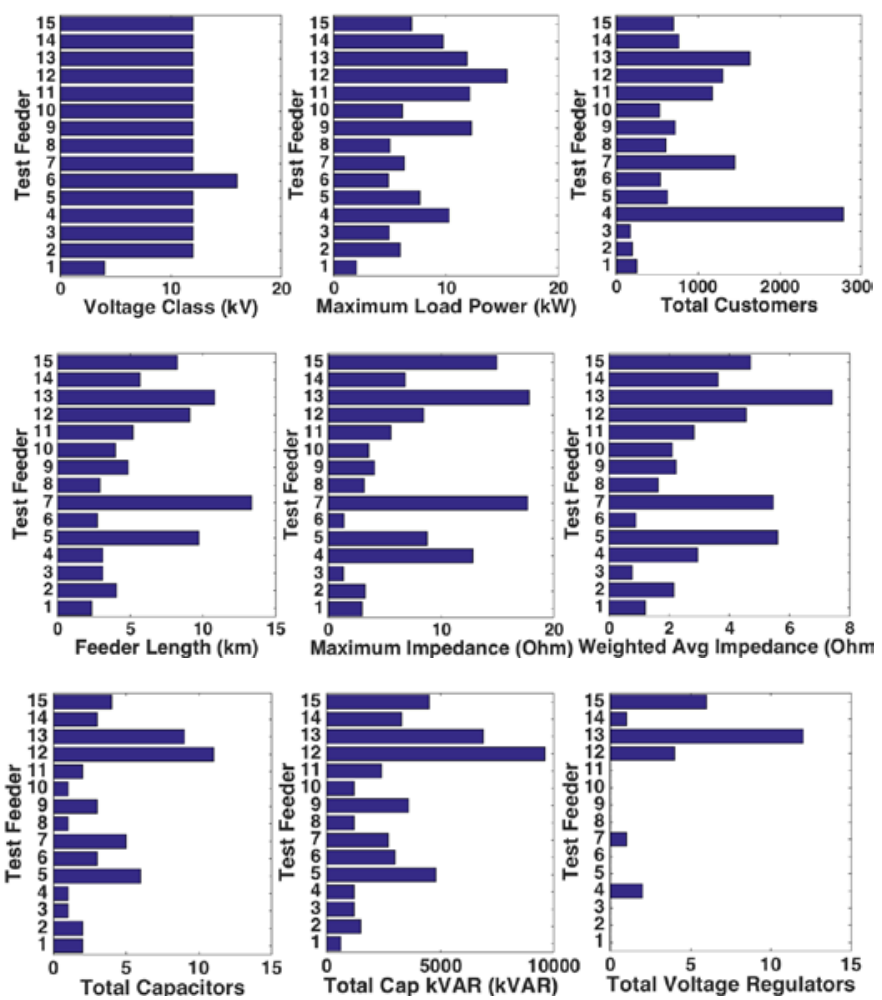

Fig. 1. Key characteristics of fifteen test feeders.

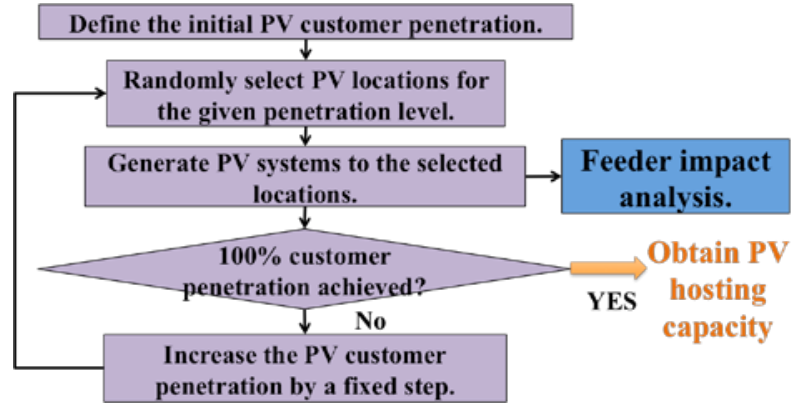

Fig. 2. The procedure of generating PV deployments into the test feeder.

At each deployment step, system voltages are evaluated to check whether violations have occurred. Table I shows the voltage limits including overvoltage based on ANSI C84.1 standard [3]. The voltage deviation limit is included for the concern about voltage flicker and interaction with cap banks, line regulators, etc. [2]. Through the examination of voltage metrics for a large quantity of scenarios, feeder impact is used to determine the total amount of PV power that is likely to cause an adverse impact on the feeder. This amount of PV power is considered as the hosting capacity.

TABLE I

Voltage Limits For Evaluating PV Hosting CAPACITY

\begin{tabular}{|c|c|c|}
\hline Criterion & Description & Threshold \\
\hline Overvoltage & Voltage magnitude. & $1.05 \mathrm{pu}$ \\
\hline Voltage & Deviation in voltage from no PV & $0.03 \mathrm{pu}$ at primary \\
Deviation & case. & $0.05 \mathrm{pu}$ at secondary \\
\hline
\end{tabular}

For each feeder, 50 different scenarios of PV deployments are studied, and each scenario also has fifty different cases spreading from $2 \%$ customer penetration to $100 \%$ customer penetration. Two loading scenarios including daytime (10 am -
2 pm) peak load and daytime off-peak load are both studied, and the smaller value between the hosting capacities obtained for two loading scenarios is used as the final hosting capacity. Thus, a total of $5000 \mathrm{PV}$ scenarios with various PV penetrations are studied to obtain the hosting capacity. Fig. 3 shows the hosting capacity results for fifteen feeders, given in percentage of peak load.

Each graph has four or five bars including primary voltage deviation (PriVdev), primary overvoltage (PriOV), capacitor overvoltage (CapOV), capacitor voltage deviation (CapVdev) and regulator voltage deviation (RegVdev). If the feeder doesn't have voltage regulator, the fifth bar, RegVdev, is not plotted. There are three regions marked with different colors: the light yellow region means no violation happens; the orange region means that some PV deployment scenarios cause adverse impact on system voltage; and the red region means that all PV deployment scenarios cause violations on system voltage. It is therefore the boundary between the first two regions is the maximum PV power that the feeder can host without causing any adverse impact on the defined voltage metrics. The minimum value among all four (five if the voltage regulator exists) bars is just the PV hosting capacity of the feeder without further consideration.

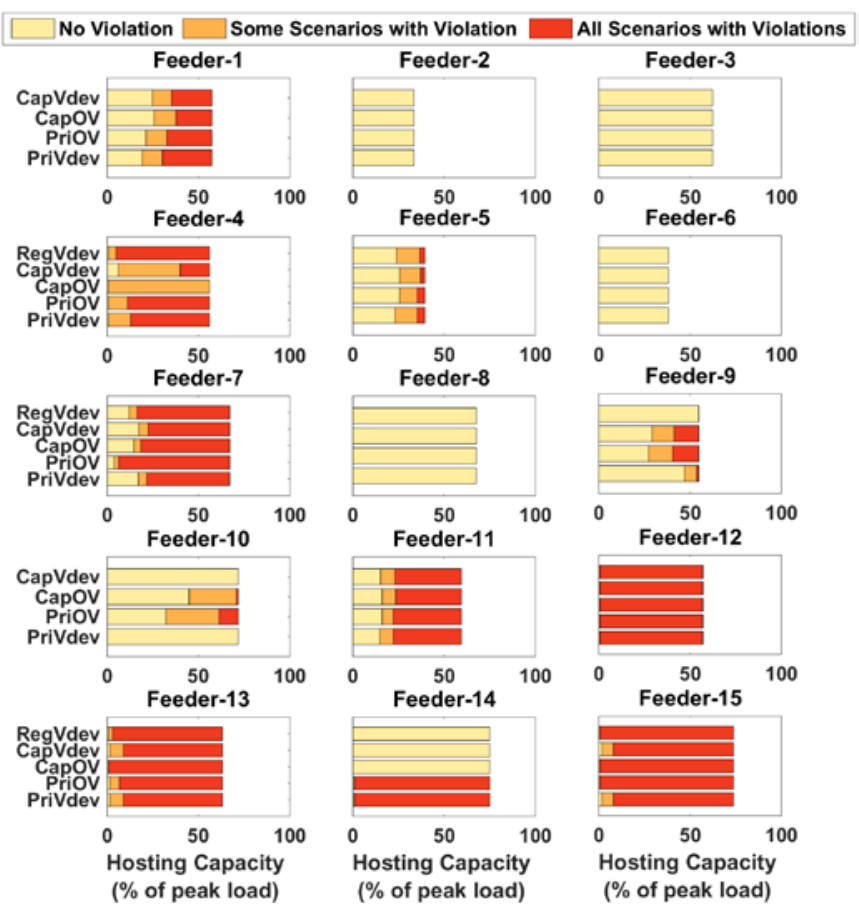

Fig. 3. Hosting capacity results of fifteen test feeders.

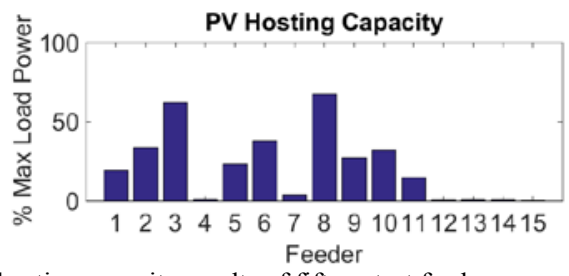

Fig. 4. PV hosting capacity results of fifteen test feeders.

Fig. 4 summarizes the final PV hosting capacities of fifteen feeders. Feeders 4, 7, 12, 13, 14 and 15 have much lower hosting capacities compared with all others. These six feeders are the only ones that have voltage regulators among fifteen 
feeders, so it is indicated that the feeder with voltage regulator has low capability to host PVs. In fact, Fig. 1 has shown that these six feeders are generally long and of high impedance, which makes the adverse voltage impacts more likely.

The hosting capacities of fifteen test feeders differ considerably, ranging from $1 \%$ to over $60 \%$ of peak load. This indicates that certain feeder characteristics might heavily influence PV hosting capacity. Fig. 5 plots the correlation between some feeder characteristics and PV hosting capacity, and the black line is the 2-order polynomial-fitting curve obtained from the scatter points. Fifteen dots with different colors represent the results for fifteen test feeders.
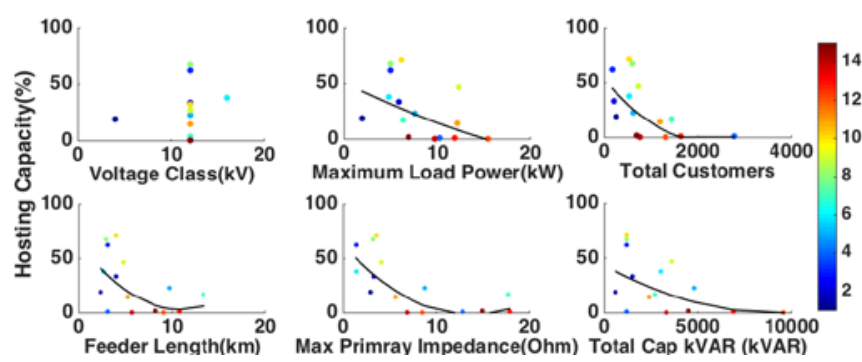

Fig. 5. PV hosting capacity v.s. feeder characteristics.

It is difficult to conclude a direct correlation between PV hosting capacities with a single feeder characteristic because the determined hosting capacity is result of multiple factors. In general, a feeder with higher voltage class, more loads and larger impedance is more likely to host more PVs. Among all six feeder characteristics, the primary impedance has the most correlation with the hosting capacity and the fitting curve better matches the collected data.

\section{InVESTIGATION ON THE FACTORS AFFECTING PV HOSTING CAPACITY}

\section{A. PVLocations}

The hosting capacity solved using the stochastic analysis is based on the assumption that all customers in the feeder are considered as candidate PV locations. However, specific PV locations could strongly affect the total amount of PV power that is allowed to penetrate into the feeder. A locational sensitivity study was conducted in [4] and the PV hosting capacity was evaluated by selecting PV customers based on the primary impedance, distance from the substation and phase connection. It was proved that the PV hosting capacity is highly location sensitive. This paper studies the PV hosting capacities of fifteen test feeders by restricting the candidate PV customers within $50 \%$ of maximum primary impedance and feeder length, respectively. Fig. 6 and Fig. 7 show the results of this screening technique.

Compared with the initial hosting capacity results given in Fig. 2, the hosting capacities of feeders 1, 4, 9, 10, 11, 13, 15 all get increased after restricting PV locations. Respectively for restricting PV locations within 50\% of feeder length and maximum primary impedance, the hosting capacity of feeder1 is increased from $19 \%$ of peak load to $33.5 \%$ and $33.3 \%$; feeder-9 is increased from $27.2 \%$ to $30.2 \%$ and $34.1 \%$; feeder10 is increased from $32.2 \%$ to $71.8 \%$ and $71.8 \%$. The hosting capacities of feeders 4 and 15 are both slightly increased. The hosting capacities of feeders 11 and 13 are reduced for distance restriction but increased for impedance restriction.

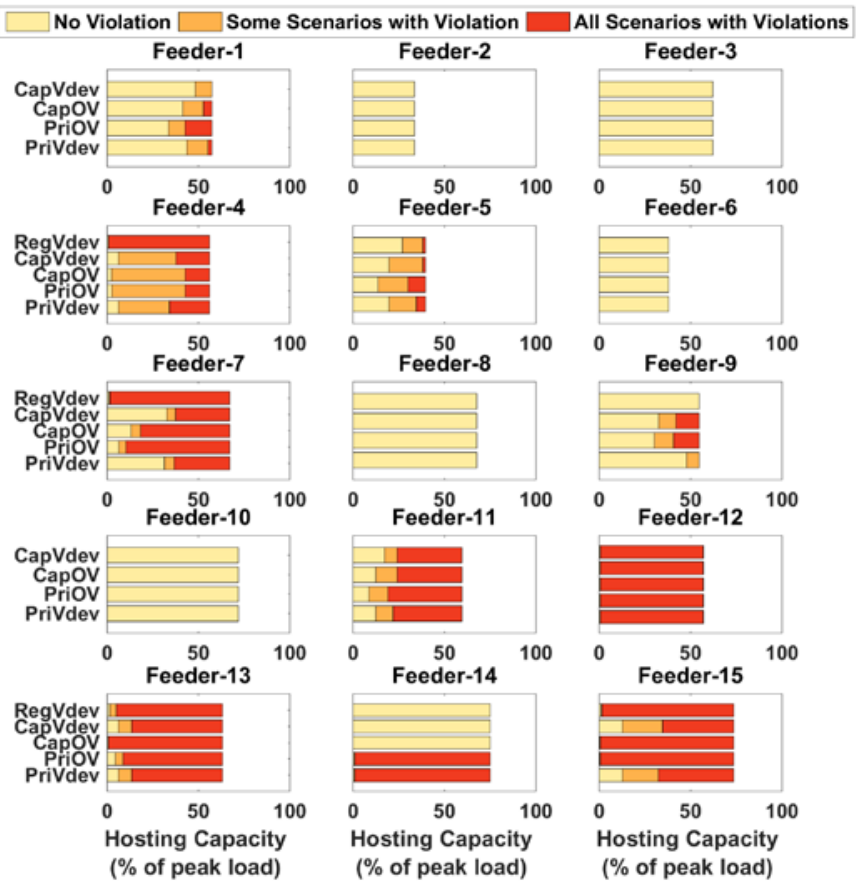

Fig. 6. Hosting capacity results of fifteen test feeders after restricting all PV locations within $50 \%$ of feeder length.

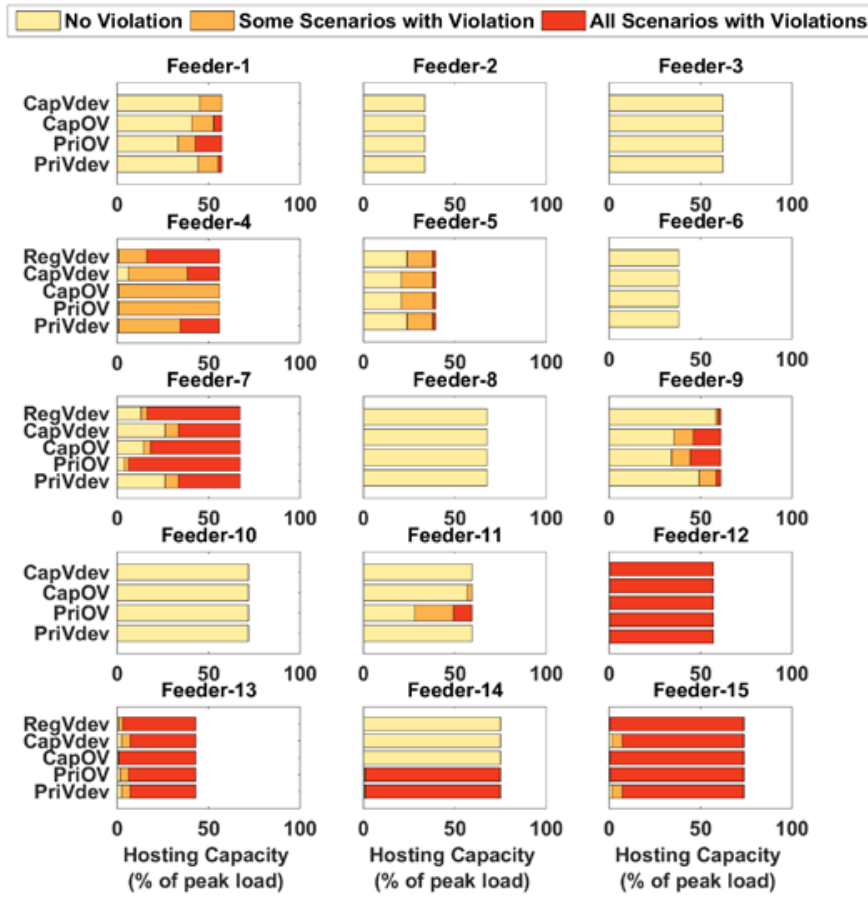

Fig. 7. Hosting capacity results of fifteen test feeders after restricting all PV locations within $50 \%$ of maximum primary impedance.

The hosting capacities of feeders 5 and 7 get reduced: feeder-5 is reduced from $23.22 \%$ to $13.8 \%$ and $20.8 \%$, and feeder- 7 is reduced from $3.84 \%$ to $1.30 \%$ and $3.83 \%$.

The hosting capacities of feeders 12 and 14 do not change. The hosting capacities of feeders 2, 3, 6 and 8 are also the same as the initial values, and these four feeders have no adverse impact even at the $100 \%$ PV customer penetration all the time, so no conclusion can be drawn from these feeders. 
In summary, PV hosting capacities of most test feeders can be increased after restricting PV locations closer to the substation. And, restricting PV locations based on the primary impedance has better performance than restricting PV locations based on the feeder length.

\section{B. PV Power Factors}

\section{(1) Unified Constant Power Factor}

The initial study is conducted by assuming the unity power factor for all PV inverters. However, the reactive power plays an important role in supporting voltages, and the hosting capacity might be affected by changing the power factor of PV inverter. Thus, three different power factors, including 0.98 , 0.95 and 0.9 leading, are assigned to all PV inverters, respectively, and the corresponding PV hosting capacity results are compared in Fig. 8.

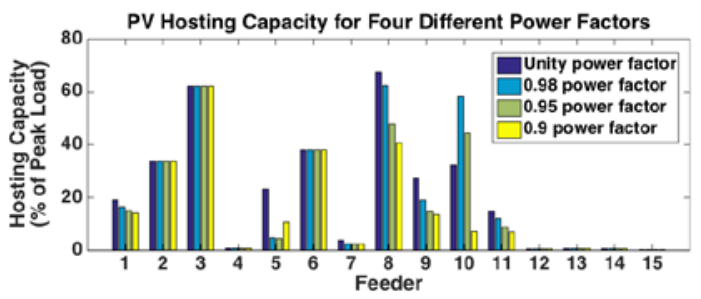

Fig. 8. PV hosting capacity results of fifteen test feeders after assigning three different power factors for all PV inverters.

The hosting capacities of feeders 1, 7, 8, 9, 11 are decreasing gradually with the leading power factors reduced. The hosting capacity of feeder 5 is highest under unity power factor but lowest under 0.95 power factor. The hosting capacity of feeder 10 can be increased if the power factor is changed to 0.98 or 0.95 . Thus, it is concluded that PV hosting capacity is greatly affected by the power factor. However, the smaller leading power factor will cause more reactive power generating from PV inverters into the feeder, the hosting capacity is not necessarily decreasing. This paper only studies the constant leading power factor, and the impact of constant lagging power factor will be included in the future.

\section{(2) Volt/VAR Control}

Different from the unified constant power factor, volt/var control can automatically adjust the reactive power output from PV inverters based on the voltage. Fig. 9 shows the typical curve to achieve volt/var control functionality. The control input is the voltage at the inverter terminal bus, $V_{\text {inv }}$. If $V_{i n v} \leq \mathrm{V} 1$, the inverter will operate in capacitive mode by generating reactive power $\mathrm{Q} 1$. If $\mathrm{V} 1<V_{i n v} \leq \mathrm{V} 2$, the reactive power generated from the inverter is computed from the interpolation between $(\mathrm{V} 1, \mathrm{Q} 1)$ and $(\mathrm{V} 2, \mathrm{Q} 2)$. If $\mathrm{V} 2<V_{i n v} \leq$ $\mathrm{V} 3$, the reactive power output is zero, and this range is referred as the deadband. When $V_{i n v}>\mathrm{V} 3$ the inverter will change to the inductive mode by consuming the reactive power following the curve between (V3,Q3) and (V4,Q4).

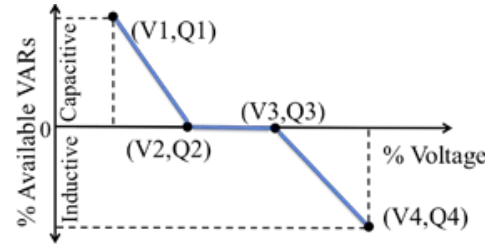

Fig. 9. Typical curve to achieve Volt/VAR control function.
The following setting points are used in the study, as

$$
\left\{\begin{array}{c}
(V 1, V 2, V 3, V 4)=(0.95 p u, 1 p u, 1 p u, 1.05 p u) \\
(Q 1, Q 2, Q 3, Q 4)=(100 \%, 0 \%, 0 \%, 100 \%)
\end{array}\right.
$$

The available reactive power $Q_{\text {available }}$ is determined by

$$
Q_{\text {available }}=\sqrt{\text { inverter rating }{ }^{2}-P V \text { active power }}{ }^{2}
$$

The hosting capacities of fifteen test feeders are shown with the volt/var functionality enabled in Fig. 10. Except feeders 2, $3,6,8$ whose hosting capacities do not change, the hosting capacities for both primary overvoltage and capacitor bus overvoltage in all other feeders are increased greatly compared with the initial values. Thus, this indicates that volt/var control is quite effective at relieving the overvoltage problems caused by PV real power injection. Taking feeder-11 as an example, Fig. 11 shows the reactive power output from PV systems at the $100 \%$ customer penetration for one deployment scenario. Most values are negative, which means most PV inverters are consuming reactive power instead of generating the reactive power into the feeder. This is because that the consumption of reactive power can help reduce voltage magnitude and avoid the overvoltage problem caused by the high PV power.

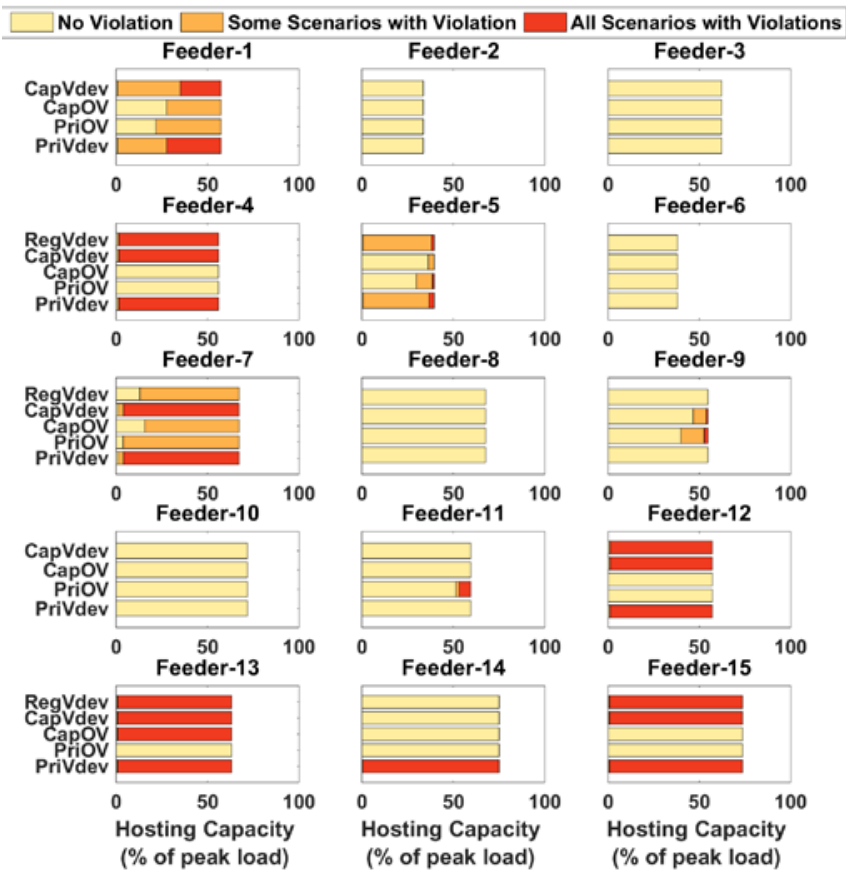

Fig. 10. PV hosting capacity results of fifteen test feeders after applying the Volt/VAR control for all PV inverters.

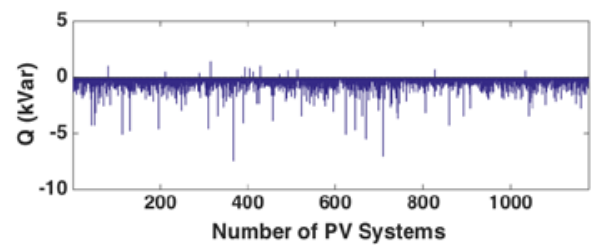

Fig. 11. PV hosting capacity results of fifteen test feeders after applying the Volt/VAR control for all PV inverters.

However, the voltage adjustments along the feeder due to the application of volt/var control can cause more voltage deviations (measured from the base case), which will make the voltage deviation-based hosting capacity lower. In order to compromise between the overvoltage and voltage deviation, 
some techniques can be utilized, such as increasing controller deadband and volt/var optimization.

\section{AdVANCED TEChNOlOgIES TO INCREASE PV Hosting CAPACITY}

The above investigations have shown that PV hosting capacity can be increased by restricting PV locations closer to the substation, adjusting the power factor of PV inverter, and applying volt/var control. Correspondingly, three advanced technologies are proposed to help increase hosting capacity.

\section{A. Feeder Reconfiguration}

Since PV locations affect the hosting capacity significantly and the higher hosting capacity is more likely to be obtained if the primary impedances of PV buses are lower, utilities are encouraged to restrict PV locations by approving the PV interconnection requests within the location limits. In addition, some technical approaches can be used to alter the distances and primary impedances of PV buses by taking use of the existing distribution assets.

Feeder reconfiguration is generally used to reduce energy losses and improve voltages [5]. But some recent studies [6] have shown its capability of improving the distributed generation (DG) hosting capacity. With the objective of maximizing DG power in the feeder, the optimal topology is determined by solving the optimization problem. And, because system topology is changed after reconfiguring the network, both distances and impedances of all PV locations will become different. Thus, the objective of the reconfiguration problem can be formulated as restricting the primary impedances of PV locations within the limits.

\section{B. PV Power Factor Setting}

The power factors of PV inverters affect the PV hosting capacity greatly, so utilities can enforce the power factor setting policy on PV customers. And, in theory, the optimal PV power factor can be obtained by solving the optimization problem with the objective of maximizing the PV power in the feeder. The optimization problem can be defined in two ways: all PV inverters have a unified power factor, and each PV inverter has its unique power factor for optimal operation.

\section{Volt/var Optimization}

Volt/var control plays an important role on improving the voltage profile, so utilities can encourage PV customers to install PV inverters with volt/var functional capability. Different volt/var functions will provide different var support. In order to get the most voltage improvement through var support, an optimal volt/var functional curve could be determined, and this will lead to the optimal decision for both $V_{i}$ and $Q_{i}(i=1,2,3,4)$.

\section{Generic Optimization Problem Formulation}

All three above approaches can be realized by solving the optimization problem, defined as

$$
\begin{aligned}
& \max \sum_{i=1}^{K} P_{P V, i}(S W, p f, V V O) \\
& \text { s.t. }\left\{\begin{array}{l}
g(e, f, u)=0 \\
h(e, f, u) \leq 0
\end{array}\right.
\end{aligned}
$$

where, $P_{P V, i}$ is the active power output from PV system- $i$, and $u$ denotes the decision variables in the optimization problem. There are three types of decision variables including (1) $S W$ : the states (0 for opened, 1 for closed) of all available feeder switches; (2) pf: the power factors of all PV systems. (3) VVO denotes the setting points for the Volt/VAR curve.

The constraints $g$ and $h$ include power flow, voltage limits, thermal limits, topology limits, PV limits and other userdefined limits. In sum, the formulated optimization problem is a constrained, mixed-integer nonlinear optimization problem. Both commercial solvers and self-written algorithms can be used to solve this optimization problem.

\section{Simulation TOOL}

All above studies were conducted by using the simulation tool developed by the authors. Fig. 12 gives a screenshot of the tool. More information is available by contacting the authors.

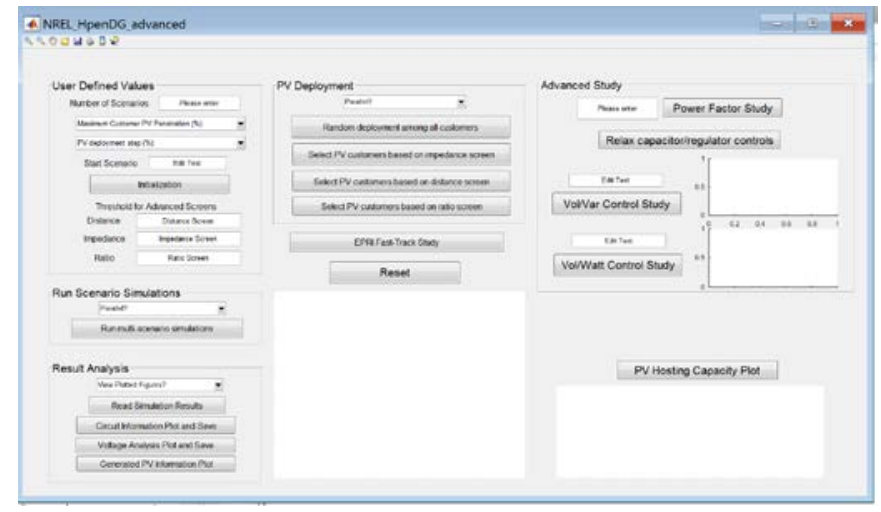

Fig. 12. PV hosting capacity analysis tool developed by the authors.

\section{CONCLUSIONS AND FUTURE WORK}

This paper studies the distributed PV hosting capacity in distribution feeders and investigates several factors affecting the hosting capacity. Based on the simulation results, this paper also proposes relative approaches to increase PV hosting capacity. At present, only the generic optimization problem is proposed, and the detailed studies about the optimization problem formulation and methodology are undergoing and will be included in future.

\section{REFERENCE}

[1] Electric Rule No. 21: Generating Facility Interconnections, Cal. P.U.C. 34818-E, January 2015.

[2] Stochastic analysis to determine feeder hosting capacity for distributed solar PV, Electric Power Research Institute (EPRI), Palo Alto, CA: 2012. 1026640.

[3] American National Standard for Electric Power Systems and EquipmentVoltage Ratings (60 Hertz), NEMA ANSI C84.1-2011, 2011.

[4] F. Ding, B. Mather, N. Ainsworth, P. Gotseff and K. Baker, "Locational sensitivity investigation on $\mathrm{PV}$ hosting capacity and fast track $\mathrm{PV}$ screening," accepted by 2016 IEEE T\&D Conference and Exposition.

[5] F. Ding and K. Loparo, "Feeder reconfiguration for unbalanced distribution systems with distributed generation: a hierarchical decentralized approach," IEEE Trans. Power Systems, In Press.

[6] F. Capitanescu, L. F. Ochoa, H. Margossian and N. D. Hatziargyriou, "Assessing the potential of network reconfiguration to improve distributed generation hosting capacity in distribution systems," IEEE Trans. Power Systems, vol. 30, no. 1, pp. 346-356, Jan. 2015. 